\title{
Putting PHDs to work: PHF11 clears the way for EXO1 in double-strand break repair
}

\author{
Karl E. Zahn and Roger A. Greenberg \\ Department of Cancer Biology, Department Pathology, Abramson Family Cancer Research Institute, Basser Research Center for \\ BRCA, Perelman School of Medicine, University of Pennsylvania, Philadelphia, Pennsylvania 19104, USA
}

\begin{abstract}
In this issue of Genes \& Development, Gong and colleagues (pp. 46-58) bring to light a functional role for plant homeodomain finger 11 (PHF11) in $5^{\prime}$ end resection at DNA double-strand breaks (DSBs). Using the proteomics of isolated chromatin segments (PICh) technique to purify deprotected telomeres, PHF11 was enriched as cells mounted a DNA damage response (DDR) against exposed chromosome ends. The study reveals interactions between PHF11 and multiple DNA repair proteins and suggests that PHF11 mediates 5' end resection by negotiating RPA-coated DNA repair intermediates. This finding provides a novel context for mediator-catalyzed RPA exchanges during the multistep process of homologous recombination (HR).
\end{abstract}

Exposed free DNA ends trigger the DNA damage response (DDR), bringing the cell cycle to a halt and giving time to repair toxic DNA double-strand breaks (DSBs). DSBs are mended by two predominant pathways, known as nonhomologous end-joining (NHEJ) and homologous recombination (HR). HR requires homologous regions of intact, undamaged DNA for template-directed repair. For this reason, HR provides a high-fidelity mechanism adapted to S phase and G2, during which replicated sister chromatids are present.

The choice to repair DSBs by NHEJ or HR is a tightly regulated process controlled accordingly by mechanisms sensitive to cell cycle status. $5^{\prime}$ resection at the DSB junction commits the repair process to HR or other related backup pathways requiring homology, such as singlestrand annealing (SSA) or alternative end-joining. During $S$ phase, the breast cancer suppressor protein BRCA1 facilitates initial $5^{\prime}$ end resection by allowing MRE11- and CtIP-dependent generation of a short $3^{\prime}$ overhang, generally $>100$ nucleotides (nt). This provides the substrate for extensive resection by EXO1 and DNA2, which exposes the 3 ' terminus destined for invasion into homologous regions

[Keywords: PHF11; EXO1; RPA; ATR; DSB; resection; homologous recombination]

Corresponding author: rogergr@mail.med.upenn.edu

Article is online at http://www.genesdev.org/cgi/doi/10.1101/gad.295923.

117. of the sister chromatid, leading to error-free repair of the DSB junction by HR (Fig. 1).

The single-stranded binding protein RPA inhibits the formation of spurious hairpins and other forms of undesirable annealing by coating the nascent $3^{\prime}$ overhang. This may also create a topological obstruction able to resist processive $5^{\prime}$ resection machinery. Interestingly, RPAcoated ssDNA is also known to stimulate the proteinstripping activities of BLM helicase and exonuclease/ helicase DNA2 to enact 5' end resection (Symington and Gautier 2011), indicating a complex relationship that encompasses both inhibitory and stimulatory activities toward resection. However, the precise choreography by which the $5^{\prime}$ resection apparatus circumvents RPA-mediated blockades in vivo stands as an open question. In this issue of Genes \& Development, Gong et al. (2017) identified plant homeodomain (PHD) finger 11 (PHF11) at uncapped telomeres by the proteomics of isolated chromatin segments (PICh) technique (Déjardin and Kingston 2009) and subsequently demonstrated an essential role for this new DDR factor in $5^{\prime}$ resection. PHF11 was described previously as a likely transcription factor gene adjacent to the IgE locus and associated with asthma and other inflammatory conditions (Zhang et al. 2003). PHF11 encodes a zinc-binding protein due to an extended PHD finger and is expressed as two alternatively spliced isoforms, with the shorter variant constructed as a 39-amino-acid $\mathrm{N}$-terminal truncation. PHD fingers are known proteinprotein interaction motifs, recognizing methylated lysine residues on histone tails (Wysocka et al. 2006), for example. The extended PHD finger consists of two parts: The pre-PHD region binds a single zinc, leading to a loop with some a-helical character. C-terminal to this is the PHD finger motif, where two additional zinc ions bind (Liu et al. 2014). Interestingly, of the DDR binding partners identified by Gong et al. (2017), only RPA required the PHD finger to interact with PHF11. EXO1, the MRE11RAD50-NBS1 complex, BARD1, and DNA2 could be pulled down by a PHF11 deletion that lacked the PHD

(C) 2017 Zahn and Greenberg This article is distributed exclusively by Cold Spring Harbor Laboratory Press for the first six months after the full-issue publication date (see http://genesdev.cshlp.org/site/misc/ terms.xhtml). After six months, it is available under a Creative Commons License (Attribution-NonCommercial 4.0 International), as described at http://creativecommons.org/licenses/by-nc/4.0/. 


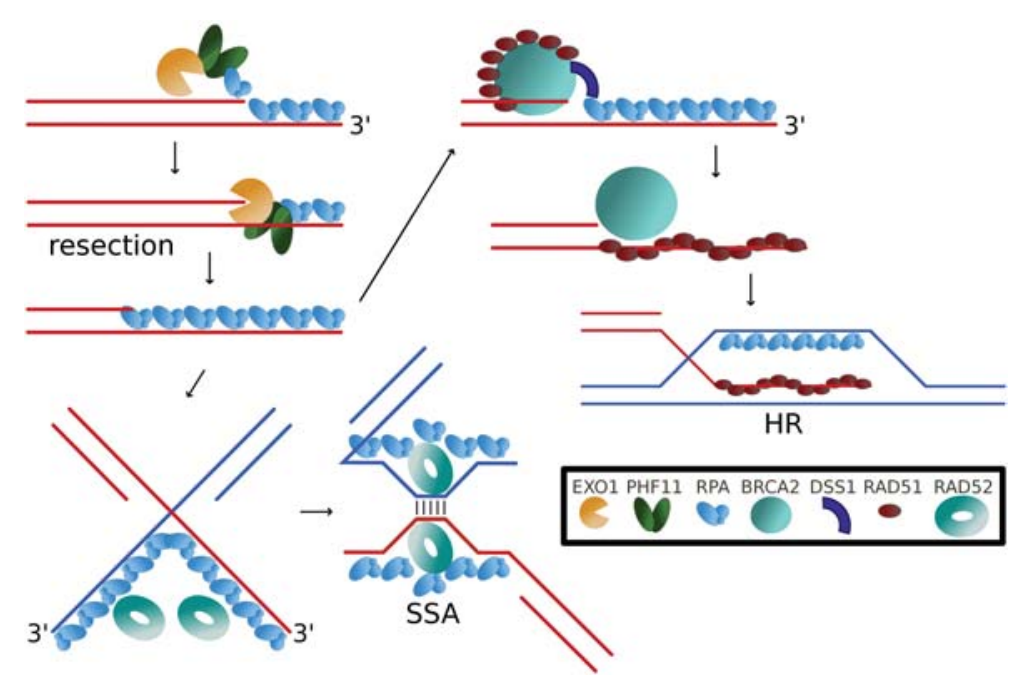

Figure 1. Plant homeodomain finger 11 (PHF11) mediates access to the $5^{\prime}$ recessed DNA terminus: The partially resected substrate generated by the MRE11RAD50-NBS1 complex is not readily accessible by EXO1 due to the presence of RPA on the ssDNA overhang. PHF11 mediates the removal of RPA, giving access of the $5^{\prime}$ terminus to EXO1 (or DNA2) for longrange resection. Two parallel pathways, HR and SSA, encounter subsequent RPA-mediated obstacles. BRCA2, with assistance from the acidic protein DSS1 (Zhao et al. 2015, 1), displaces RPA in order to load the RAD51 recombinase onto the ssDNA. Once assembled, the RAD51 nucleoprotein filament is able to invade homologous regions of sister chromatid for DSB repair by HR. The RAD52 protein must negotiate RPA-bound ssDNA to anneal short homologous regions, leading to repair of the DNA double helix by SSA. finger but retained the pre-PHD region. Importantly, PHF11 stimulated EXO1 resection activity by up to 10fold in vitro only in the context of RPA-coated substrates. RPA and PHF11 localized in cells to foci of DNA damage with similar kinetics, and PHF11 knockout diminished the activity of ATR kinase on CHK1, presumably due to failed resection and reduced abundance of RPA-coated ssDNA. Collectively, all experiments indicated that PHF11 acts as a gatekeeper for extensive $5^{\prime}$ resection in DNA repair by mediating RPA-coated intermediates.

DSB repair is crucial to maintaining genomic integrity in all organisms and is therefore well conserved across species. Germline mutations in the BRCA1 or BRCA2 genes confer breast cancer with high penetrance, and knockouts of either in mice is embryonic-lethal. The BRCA1 protein consists of an N-terminal RING domain (harboring E3 ubiquitin ligase activity) and tandem BRCT repeats at the $\mathrm{C}$ terminus known to interact with phosphorylated DDR proteins. The paralog BARD1 forms a heterodimer with BRCA1. The Arabidopsis thaliana genome conserves HsBRCA1 and HsBARD1 homologs, which code for proteins with overall domain architectures comparable with heir human equivalents. A notable exception exists in that protein products of AtBRCA1 and AtBARD1 each conserve a PHD finger between the RING fingers and BRCT repeats (Trapp et al. 2011), a domain not preserved in vertebrate homologs. Interestingly, no clear PHF11 homolog exists in plants. Might the PHD fingers of the AtBRCA1-AtBARD1 heterodimer function like PHF11 during $5^{\prime}$ resection in plants, thus hinting at a conserved reaction mechanism? Although the reported interaction between BRCA1-BARD1 and PHF11 will require further investigation to evaluate this insight, the study from Gong et al. (2017) demonstrates clearly that PHD fingers are not unique to the DSB repair complexes of plants. The necessity to mediate RPA during resection emerges from the current work, which was not altogether unexpected considering that RPA negotiation is fundamental at other steps of HR (Fig. 1). The BRCA2 protein is a known mediator of RAD51 nucleofilament formation on
RPA-coated ssDNA (Yang et al. 2005). The small acidic protein DSS1 assists BRCA2 in catalyzing this transition from RPA- to Rad51-coated ssDNA (Zhao et al. 2015). This activity is essential to seed the RAD51 filament, which can then assemble toward the $3^{\prime}$ terminus. In a separate example, RAD52 mediates RPA displacement during SSA (Grimme et al. 2010), an error-prone form of homology-directed DNA repair. Finally, recent studies suggest that RPA ubiquitylation provides another means with which to navigate this roadblock to ssDNA access (Elia et al. 2015), although it is unclear whether this involves disruption of RPA-ssDNA complexes.

The work of Gong et al. (2017) thus begins a new chapter in which the motif of RPA mediation is expounded, demonstrating the universality of dealing with RPA during each step of HR. As noted above, PHF11 also interacts with several other repair factors, and it is still an open question as to the relative importance of its RPA displacement activities in comparison with its interactions with these myriad DNA repair and resection factors. Given that PHF11 deficiency was not equivalent to knockdown of EXO1 or any other associated factors in the DDR, this is consistent with either pleiotropic roles in repair or that PHF11 acts at an early stage of DNA processing that affects the functions of multiple repair proteins. Finally, it is still unclear how PHF11 localizes to DSB sites, the answers to which might provide additional insights into its repair activities. We look forward to future studies that will probe deeper into these questions and define mechanisms by which PHF11 clears the way for DSB repair.

\section{Acknowledgments}

K.E.Z. is supported by institutional T32 training grant 5T32CA115299-10 in tumor virology at the University of Pennsylvania. R.A.G. is supported by National Institutes of Health grants GM101149, CA138835, and CA17494 and funds from the Abramson Family Cancer Research Institute and Basser Research Center for BRCA. 


\section{References}

Déjardin J, Kingston RE. 2009. Purification of proteins associated with specific genomic loci. Cell 136: 175-186.

Elia AEH, Wang DC, Willis NA, Boardman AP, Hajdu I, Adeyemi RO, Lowry E, Gygi SP, Scully R, Elledge SJ. 2015. RFWD3-dependent ubiquitination of RPA regulates repair at stalled replication forks. Mol Cell 60: 280-293.

Gong Y, Handa N, Kowalczykowski SC, de Lange T. 2017. PHF11 promotes DSB resection, ATR signaling, and HR. Genes Dev (this issue). doi: 10.1101/gad.291807.116.

Grimme JM, Honda M, Wright R, Okuno Y, Rothenberg E, Mazin AV, Ha T, Spies M. 2010. Human Rad52 binds and wraps single-stranded DNA and mediates annealing via two hRad52ssDNA complexes. Nucleic Acids Res 38: 2917-2930.

Liu Z, Li F, Ruan K, Zhang J, Mei Y, Wu J, Shi Y. 2014. Structural and functional insights into the human Borjeson-ForssmanLehmann syndrome-associated protein PHF6. I Biol Chem 289: 10069-10083.

Symington LS, Gautier J. 2011. Double-strand break end resection and repair pathway choice. Annu Rev Genet 45: 247-271.
Trapp O, Seeliger K, Puchta H. 2011. Homologs of breast cancer genes in plants. Front Plant Sci 2: 19.

Wysocka J, Swigut T, Xiao H, Milne TA, Kwon SY, Landry J, Kauer M, Tackett AJ, Chait BT, Badenhorst P, et al. 2006. A PHD finger of NURF couples histone H3 lysine 4 trimethylation with chromatin remodelling. Nature 442: 86-90.

Yang H, Li Q, Fan J, Holloman WK, Pavletich NP. 2005. The BRCA2 homologue Brh2 nucleates RAD51 filament formation at a dsDNA-ssDNA junction. Nature 433: 653-657.

Zhang Y, Leaves NI, Anderson GG, Ponting CP, Broxholme J, Holt R, Edser P, Bhattacharyya S, Dunham A, Adcock IM, et al. 2003. Positional cloning of a quantitative trait locus on chromosome 13q14 that influences immunoglobulin E levels and asthma. Nat Genet 34: 181-186.

Zhao W, Vaithiyalingam S, San Filippo J, Maranon DG, JimenezSainz J, Fontenay GV, Kwon Y, Leung SG, Lu L, Jensen RB, et al. 2015. Promotion of BRCA2-dependent homologous recombination by DSS1 via RPA targeting and DNA mimicry. Mol Cell 59: 176-187. 


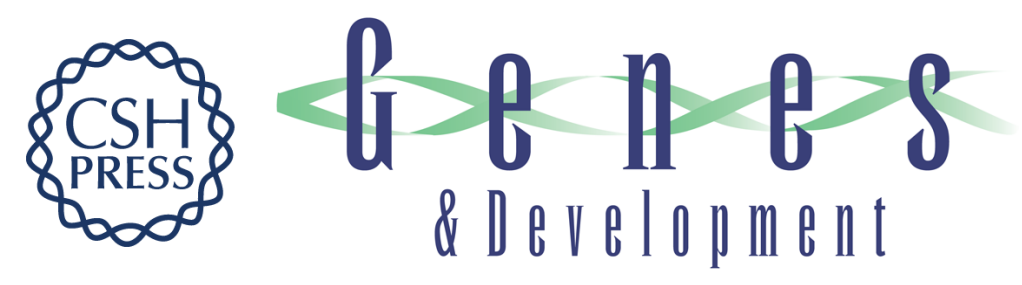

\section{Putting PHDs to work: PHF11 clears the way for EXO1 in double-strand break repair}

Karl E. Zahn and Roger A. Greenberg

Genes Dev. 2017, 31:

Access the most recent version at doi:10.1101/gad.295923.117

$\begin{array}{ll}\text { Related Content } & \text { PHF11 promotes DSB resection, ATR signaling, and HR } \\ \text { Yi Gong, Naofumi Handa, Stephen C. Kowalczykowski, et al. }\end{array}$

Genes Dev. January , 2017 31: 46-58

References This article cites 11 articles, 2 of which can be accessed free at:

http://genesdev.cshlp.org/content/31/1/3.full.html\#ref-list-1

Articles cited in:

http://genesdev.cshlp.org/content/31/1/3.full.html\#related-urls

Creative This article is distributed exclusively by Cold Spring Harbor Laboratory Press for the first Commons six months after the full-issue publication date (see

License http://genesdev.cshlp.org/site/misc/terms.xhtml). After six months, it is available under a Creative Commons License (Attribution-NonCommercial 4.0 International), as described at http://creativecommons.org/licenses/by-nc/4.0/.

Email Alerting Receive free email alerts when new articles cite this article - sign up in the box at the top Service right corner of the article or click here.

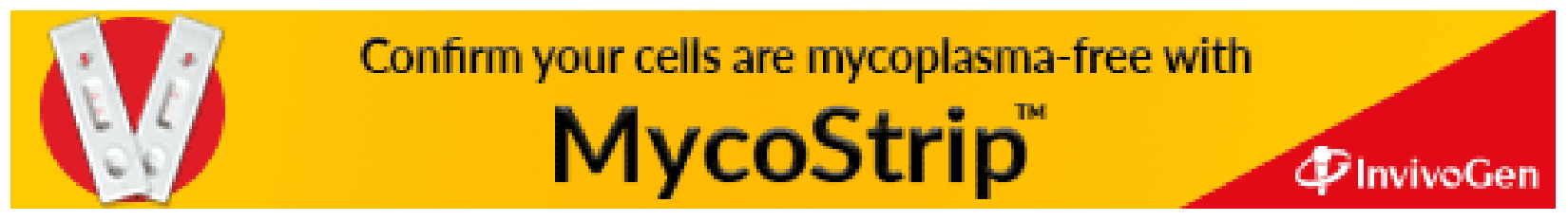

